\title{
Recent trends in ion exchange membrane research
}

\author{
Toshikatsu Sata \\ Research and Development Division, Tokuyama Soda Co., Ltd. \\ 1-1, Mikage-cho, Tokuyama City, 745, Yamaguchi Prefecture, Japan
}

\begin{abstract}
Recent trends in ion exchange membrane research are summarized from viewpoint of manufacturing ion-exchange membranes. While ion-exchange membranes used in industrial area are mostly of the polymerization types crosslinked by divinylbenzene or of perfluorocarbon types, various attempts to make new types of membranes have also been made using other polymers and different methods. For certain industrial requirements, ion-exchange membranes having an anisotropic structure are used in various areas : electrodialytic concentration of sea water, electrolysis of sodium chloride, reverse osmosis etc. And micro-structure of the membranes is also actively analyzed by various measuring methods.

Industrial applications of the membranes, being practiced, are discussed according to our experience. Electrodialysis is applied to concentration of sea water for making edible salt, demineralization of saline water, treatment of waste water and food industry. Electrolysis of sodium chloride and other solutions is also discussed. Other applications are diffusion dialysis to recover acid from waste acid solutions, and separator for battery. In this work, other various researches concerning membrane usage are explained by citing the literature.
\end{abstract}

\section{INTRODUCTION}

Ion-exchange membrane is one of the most advanced materials among functional polymers which have been studied very actively. While ion-exchange membrane has a long history in its progress, some epoch-making progresses have been made as follows : the development of homogeneous polymerization type membranes such as sulfonated and aminated styrenedivinylbenzene copolymers to replace condensation and heterogeneous membranes, the production of potable water from saline water by electrodialysis, the edible salt production from sea water by electrodialysis, the development of perfluorocarbon cation exchange membranes and the establishment of membrane chlor-alkali technology.

Ion exchange membranes are insoluble membranous materials on which ion exchange groups are bonded. The membrane is able to keep two different solutions physically separated and is simultaneously permeable to ions and water. While the target to develop better membrane varies with the intended application of the membrane, the most important thing is a high selectivity to the material to be separated with low energy consumption. Also desirable is not only selectivity between cations and anions but also selectivity among ions of same charge.

In this work, recent research trends of ion-exchange membranes are summarized. Tokuyama Soda. Co. Ltd. has been engaged in reseach and development of ion exchange membranes for about 36 years. So our recent works are also mentioned. In retrospect when an ion exchange membrane was required for a new kind of application, an eligible membrane was somehow developed. Therefore, the recent research trends will be known, if emergence of recent ion-exchange membranes usages is followed to look upon.

\section{PREPARATION METHOD OF ION EXCHANGE MEMBRANES}

\section{Cation exchange membranes and anion exchange membranes}

Most of cation and anion exchange membranes used in the industrial area are composed of derivatives of styrene-divinylbenzene copolymer, chloromethylstyrene-divinylbenzene copolymer or vinylpyridines-divinylbenzene copolymer. Besides, perfluorocarbon cation exchange membranes are used in chlor-alkali process. These membranes are mostly reinforced with backing materials in order to maintain their mechanical strength. These membranes show excellent electrochemical properties and high chemical stability in electrodialysis and electrolysis (ref. 1,2). Manufacturing of these membranes is made continuously. For example, NEOSEPTA membranes of Tokuyama Soda Co. Ltd. are continuously manufactured by "Paste Method" (ref. 3).

In addition to these membranes, other new type of ion-exchange membranes and their preparation methods are studied. One of these studies is grafting of polymerizable 
monomers to polymer film by -ray irradiation. The films used are generally polyethylene, polypropylene (ref. 4), polytetrafluoroethylene (ref. 5), PFA (ref. 6), FEP (ref. 5) and so on. While acrylic acid is mainly used as a monomer, , , -trifluoroacrylate and styrene are used in some cases (ref. 7). In general, when ion-exchange membrane is made by this method, ion exchange groups are distributed heterogeneously across the membrane cross-section (ref. 6,7). Another method is direct introduction of cation or anion exchange groups into conventional polymers such as polyethersulfone, polyphenylene oxide (ref. 8), polyvinyl chloride, polyvinylidene fluoride (ref. 9) and so on. Especially, sulfonation or chloromethylation and amination of polyethersulfone or polyphenylene oxide are studied by many. (ref. 10). As polyethersulfone has strong resistance to heat, chemicals and compaction by hydraulic pressure, most of these studies are made for the purpose of charged reverse osmosis and ultrafiltration. A method to make ion-exchange membranes to be of anisotropic structure is to form a highly crosslinked layer of anion exchange membrane over the porous polyvinylidene fluoride membrane. The membrane made by this method is suitable for diffusion dialysis (ref. 11). Another kinds of ion-exchange membrane are obtained by subsequent sulfonation of the film of which a conventional film has been impregnated with styrene and divinylbenzene for copolymerization (ref. 12), and casting the mixed solution of polystyrenesulfonic acid and other inert polymer (interpolymer membrane). The latter case is suitable for preparing charged reverse osmosis membrane (ref. 13). In order to increase the concentration of ion-exchange groups of membrane, some hydrophobic groups are introduced in the membrane matrix (ref. 14). This method gives low diffusivity of salt and low osmosis of water to the membranes.

Perfluorocarbon cation exchange membranes for chlor-alkali process have an anisotropic structure in the cross-section of the membrane. Cathode side of the membrane has a thin carboxylic acid groups layer of a given ion exchange capacity, and anode side of the membrane has a thick sulfonic acid groups layer or carboxylic acid groups layer of high ion-exchange capacity (ref. 15). There is a sulfonic acid groups membrane wherein carboxylic acid groups are introduced by chemical reactions (ref. 16,17). In these membranes, optimum concentration of catholyte is controlled by ion exchange capacity of the cathode side carboxylic acid groups layer as is shown in Fig.1 (ref. 17).

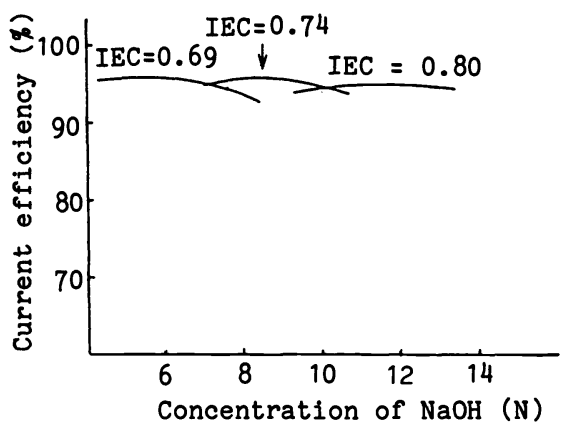

Electrolysis conditions $4.0 \mathrm{KA} / \mathrm{m} ; 90^{\circ} \mathrm{C}$

Fig. 1. Examples of optimum ion exchange capacity of perfluorocarbon carboxylic acid groups layer to the catholyte concentration (IEC : meq/g dry membrane).

New kind of ion exchange membrane reported recently is anion exchange membrane having quarternary ammonium groups which are pendent to the perfluorocarbon chain (ref. 18). This membrane is made by the following reactions :

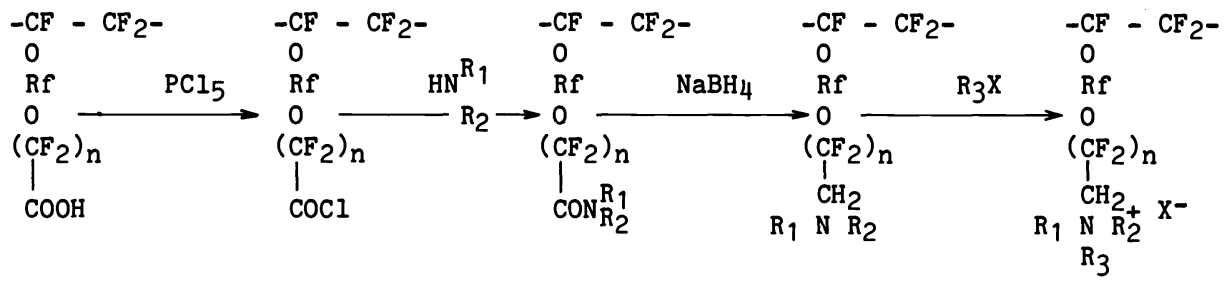

Although inorganic ion exchange membranes are also reported (ref. 19), it is difficult to use them industrially except the application to water electrolysis as a separator (ref. 20). 


\title{
Bipolar, amphoteric, mosaic ion exchange membranes and others
}

These membranes have been well-known since many years ago. Preparation methods of bipolar ion exchange membranes are recently reported as follows : introduction of cation exchange groups to one side of the membrane and then anion exchange groups to the other side ( $r$ ef. 21 ), or a cation exchange membrane and an anion exchange membrane are glued together by using polystyrenesulfonic acid as a binder (ref. 22). Similarly, it is proposed that quarternary ammonium groups are introduced into one side of perfluorocarbon sulfonic acid groups membrane by the same method as above-mentioned (ref. 23). Allied Corp reported the development of equipment for acid and base production by using a bipolar ion exchange membrane (ref. 24). Our company also developed bipolar ion exchange membrane and equipment for it. There is a report about theoretical analysis of water dissociation in the bipolar ion exchange membrane (ref. 25).

It was reported that some composition of amphoteric ion exchange membranes is selectively permeable to hydrogen ions in contrast to sodium ions (ref. 26) as is shown in Fig.2.

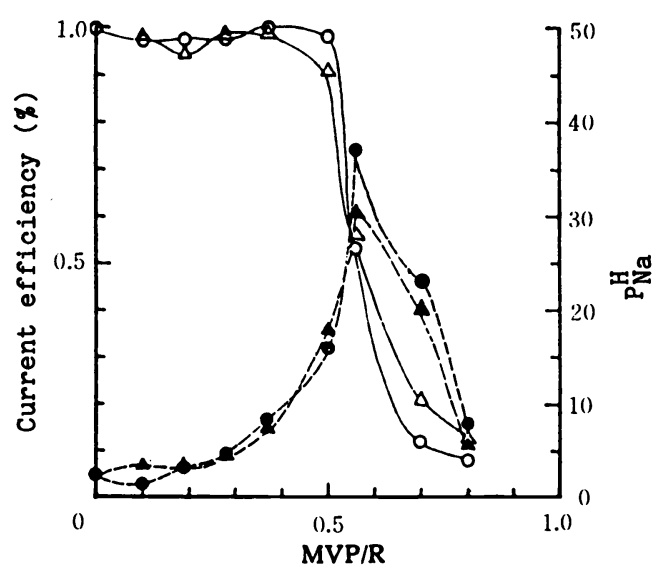

\section{Fig. 2. Relative transport number of $\mathrm{H}^{+}$to $\mathrm{Na}^{+}\left(\mathrm{P}_{\mathrm{Na}}^{\mathrm{H}}\right)$ in amphoteric ion exchange membranes (NEOSEPTA).}

\author{
MVP : 2-methyl-5-vinylpyridine \\ $R$ : total resin content \\ 0 , : quarternized membrane \\ $\Delta, \Delta:$ without quarternization
$\circ, \Delta:$ current efficiency $\bullet \bullet, \Delta: \mathrm{P}_{\mathrm{Na}}^{\mathrm{H}}$
}

Polysalt membrane (ref. 27) and snake cage membrane (ref. 28) are also amphoteric. In recent work, a thin amphoteric ion exchange membrane having sulfonic acid groups and quarternary ammonium groups over porous membrane is reported to concentrate sodium chloride while it blocks permeation of sugar through the membrane by piezodialysis (ref. 29). The amphoteric type ion exchange membranes show an interesting behavior in the separation process.

Studies on mosaic ion exchange membranes are active recently. Preparation methods are : 1) casting of multiblock copolymer composed of styrene, butadiene and vinylbenzyldimethylamine and subsequent introduction of cation and anion exchange groups into the polymer ( $\mathrm{ref} .30$ ), 2) casting of multiblock copolymer which has been prepared by ultrasonic irradiation over polystyrene copolymerizing small amount of vinylpyridines, subsequent grafting of 4-vinylpyridine to the polymer and then introduction of cation and anion exchange groups into it (mechanochemical method) (ref. 31). In general, these mosaic ion exchange membranes are used for piezodialysis : purification of amino acids (ref. 32), separation between $\mathrm{K}^{+}$and $\mathrm{Na}^{+}$(ref. 33) and concentration of salt solution (ref. 34).

It is desirable that ion exchange membranes can separate ions with the same charge. Selective permeation of certain kinds of monovalent ions is possible in electrodialysis. Such membranes made it possible to produce salt from sea water by electrodialysis. In Japan, edible salt has been made entirely by this method since 1972. The permselectivity of membrane to monovalent cation and anion is achieved by employment of anisotropic structure of membrane. Namely monovalent cation permselective membranes have a thin cationic polyelectrolyte layer over the membrane surface (ref. 35) and monovalent anion permselective membranes have a thin high cross-linked layer over the surface (ref. 36 ). Typical example of monovalent cation permselectivity of membranes is shown in Fig.3 (ref. 35). The permselectivity is caused by the difference of electrostatic repulsion force between multivalent cations and monovalent cations against cationic polyelectrolyte layer. This deduction is proved by measurements of the relative transport number between monovalent cations with different hydrated radius. In Fig.4, sodium ions rather than potassium ions permeate preferentially through the cation exchange membrane with cationic polyelectrolyte layer although the hydrated ionic radius of sodium ions is larger than that of potassium ions (ref. 35). In this connection, the measurements of permselectivity among $\mathrm{Li}^{+}, \mathrm{Na}^{+}$and $\mathrm{K}^{+}$are reported using the membrane containing lactone rings (ref. 37 ). Also there is an interesting report that the membranes made by the copolymer of styrene and various vinylpyridines show different permselectivity between chloride ions and bromide ions depending on species of vinylpyridines (ref. 38) as is shown in Fig.5. 


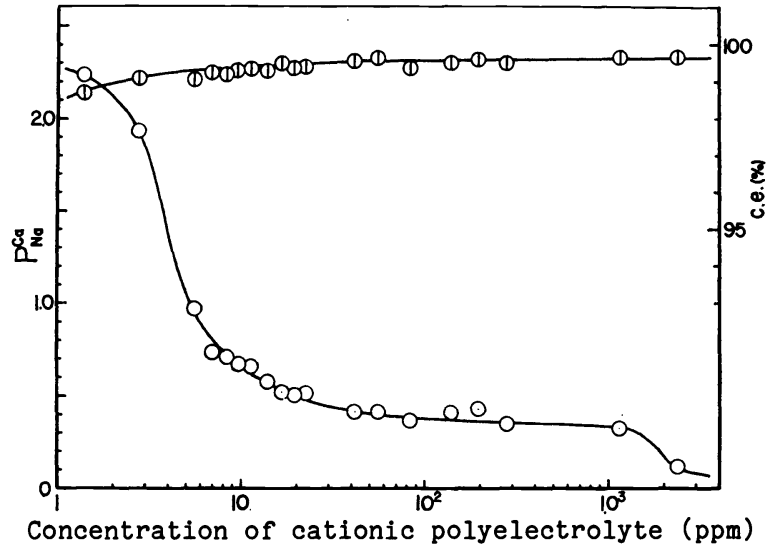

Fig. 3. Change in relative transport number $\left(\mathrm{P}_{\mathrm{Na}}^{\mathrm{Ca}}\right.$ ) of cation exchange membrane, NEOSEPTA $\mathrm{CL}-25 \mathrm{~T}$, and current efficiency in the presence of cationic polyelectrolyte.

$\circ: \mathrm{P}_{\mathrm{Na}}^{\mathrm{Ca}} ; \oplus:$ c.e. $(\%)$

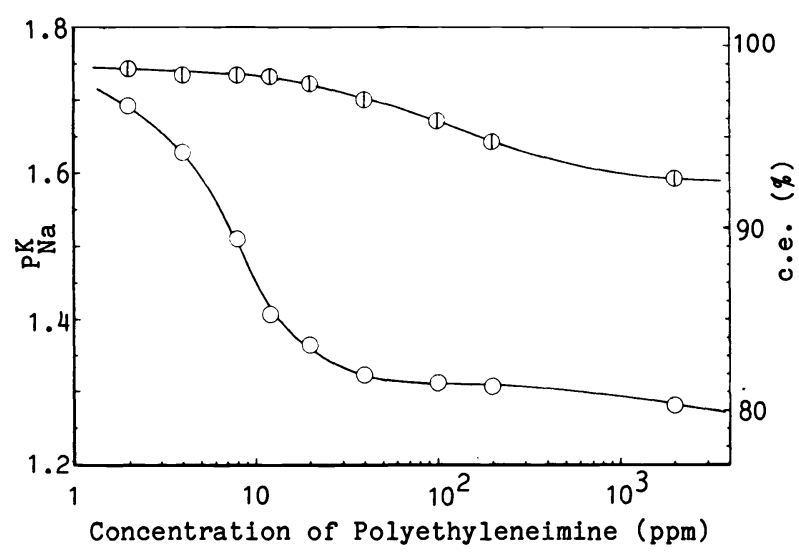

Fig. 4. Change in relative transport number $\left(\mathrm{P}_{\mathrm{Na}}^{\mathrm{K}}\right.$ ) of cation cation exchange membrane, NEOSEPTA CL-25T, and current efficiency in the presence of cationic polyelectrolyte.

$$
\circ: \mathrm{PN}_{\mathrm{Na}}^{\mathrm{K}} ; 0: \text { c.e. (q) }
$$

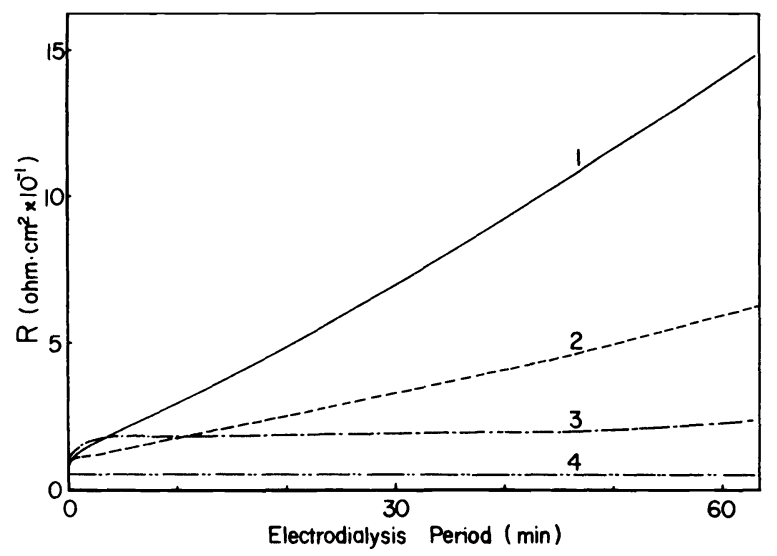

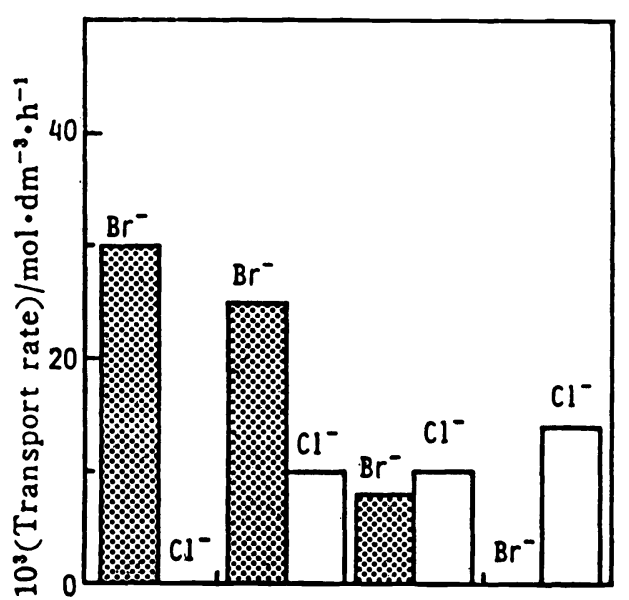

P4VPy-St P3VPy-St P2N5VPy- P2VPy-St

$(2 / 8)$

(3/7)

(3/7)

(3/7)

Fig. 5. Initial transport rate of $\mathrm{Br}^{-}$and $\mathrm{Cl}^{-}$in the membranes prepared by copolymers composed of various vinyl pyridines and styrene.

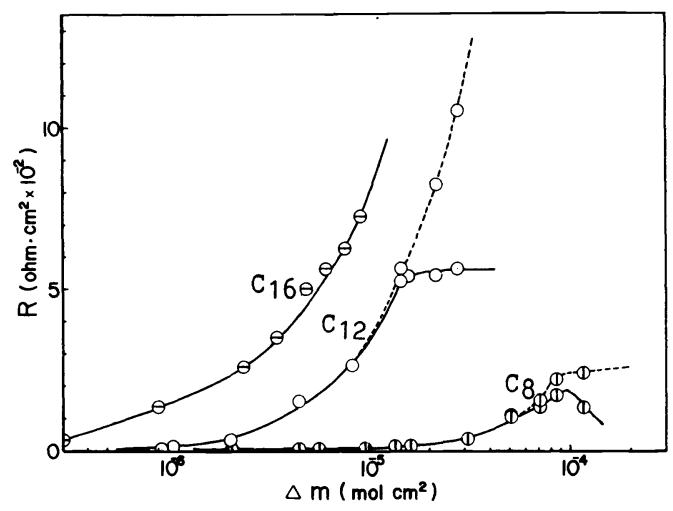

Fig. 6. Electric resistance of cation exchange membrane, NEOSEPTA CL-25T, during electrodialysis in the presence of alkyl pyridinium chloride.

D: octyl pyridinium chloride ; 0 : dodecyl pyridinium chloride ; $\theta$ : hexadecyl pyridinium chloride ; $\Delta \mathrm{m}$ : adsorbed or ion-exchanged amount of them on the membrane.

Fig. 7. Change in electric resistance of cation exchange membrane, NEOSEPTA CL-25T, in the presence of hexadecyl pyridinium chloride (HPC):

1. without cationic polyelectrolyte layer and with HPC;

2. after immersion of the membrane into cationic polyelectrolyte solution and with HPC;

3. after electrodeposition of cationic polyelectrolyte on the membrane surface and with HPC;

4. without cationic polyelectrolyte and HPC. 
Copolymer membranes of poly-4-vinylpyridine-styrene and poly-2-vinylpyridine-styrene are preferentially permeable to $\mathrm{Br}^{-}$and $\mathrm{Cl}^{-}$respectively. This is due to the difference of interactions between the membranes and anions. Of course, permselectivity between two kinds of cations is changeable to some extent by selecting the electrodialysis conditions. There is a report concerning permselectivity between nickel ions and sodium ions (ref. 39).

Other interesting report is an anion exchange membrane containing crown ether ( which do not have amino groups). It is reported that this membrane shows less $\mathrm{pH}$ change above the limiting current density and is less susceptive to organic fouling (ref. 40). When ionic organo-compounds of high molecular weight such as ionic surface active agents are contained in the solution to be electrodialyzed, electric resistance of the membrane increases remarkably. Typical examples are shown in Fig. 6 in the case of alkyl pyridinium ions against cation exchange membranes (ref. 41). This increase in resistance can be prevented by forming a thin cationic polyelectrolyte layer on the cation exchange membrane as is shown in Fig.7 (ref. 42). The similar problems in the case of anion exchange membranes are also solved by similar method.

In general, as hydrogen ions permeate easily through anion exchange membrane, acid cannot be concentrated to more than a certain level by electrodialysis at high efficiency. It is reported that anion exchange membranes of high acid-retention have been developed (ref. 43).

\section{STRUCTURE AND PROPERTIES OF ION EXCHANGE MEMBRANES}

For the purpose of improving the performance of ion-exchange membranes, micro-structure of the membrane should be clarified. At the same time, it is interesting to investigate the structure of the membrane : the phase separation of hydrophilic groups in hydrophobic polymer matrix, the distribution of ion exchange groups in the membrane, the estimation of pore size of the membrane and so on. The hydrocarbon ion exchange membranes are generally composed of derivatives of styrene-divinylbenzene copolymer and other inert polymers such as polyethylene, polyvinyl chloride and so on. It was reported that the derivatives of such copolymers are finely distributed in the inert polymer material forming microdomain because of their poor mutual compatibility (ref. 44). This is also confirmed by FarInfrared spectrum study by using sulfonated polystyrene with differentiated degrees of sulfonation (ref. 45). It is well-known that ion-exchange groups are distributed in the membrane matrix at varied concentration, as confirmed by Donnan adsorption of salt. Recently, the distribution of $\mathrm{Cu}^{2+}$ in the membrane was measured by Electron Spin Resonance. The data show that concentration of ion-exchange groups in the membrane varies locally to almost four times higher than the average concentration (ref. 46).

Development of perfluorocarbon cation exchange membranes accelerates the studies on membrane structure. The analyses of perfluorocarbon cation exchange membranes are : the NMR measurement of water distribution in the membrane matrix (ref. 47), the analysis of molecular motion by means of 19F NMR (ref. 48), the measurement of helix reversal by Infrared spectrum (ref. 49), studies on hydration of ions in sulfonic acid membrane by Infrared spectrum (ref. 50), the measurements of ${ }^{1} \mathrm{H},{ }^{19} \mathrm{~F}$ NMR and Mössbauer spectroscopy on perfluorocarbon carboxylic acid groups membrane (ref. 51) and so on. Similarly, hydration state and proton conducting mechanism in hydrocarbon ion exchange membrane were measured in detail by Infrared spectrum (ref. 52). It was reported that the ion exchange groups form clusters in the perfluorocarbon cation exchange membrane (ref. 53). Namely, most of ion exchange groups exist in such clusters, dissociate and hydrate. These clusters are mostly channeled each other. Figure 8 shows model of the cluster structure in the membrane (ref. 53) though size of the clusters varies with ion exchange capacity and species of ion-exchange groups. There are many works regarding the cluster theory (ref. 54 ). Moreover, the relationship between the current efficiency and the concentration of caustic soda in chlor-alkali process is deduced in connection with hydration of the membrane and catholyte concentration (ref. 55). Morphological effect on the membrane properties was measured on the membranes which had been obtained by blending perfluorocarbon sulfonic acid polymer, perfluorocarbon carboxylic acid polymer and perfluorocarbon sulfonamide

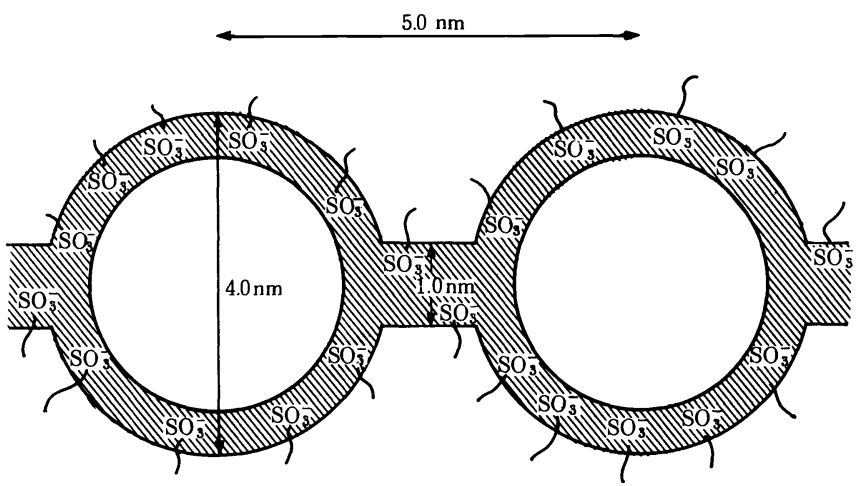

Fig. 8. Cluster-network model for perfluorocarbon sulfonic acid membranes. 
polymer (ref. 56). Other interesting works concerning analysis of the membrane structure are : the support of cluster model by measurement of the concentration of fixed ionexchange groups in the membrane (ref. 57), the evaluation of heterogeneity of the membrane by measurement of abnormal electroosmosis (ref. 58), the change in the electroosmosis and osmotic water by hydraulic pressure in accordance with ionic species ( $r e f .59$ ), permanent deformation or bulging of Nafion membrane by electric field (ref. 60), the distance between nickel ions in the wet Nafion membrane is about $3.10 \mathrm{~A}$ by $\mathrm{X}$-ray analysis (ref. 61 ) and so on. It is expected that above-mentioned studies will be reflected to prepare ion exchange membranes of high performance.

\section{APPLICATION OF ION EXCHANGE MEMBRANES TO INDUSTRY}

Many applications of ion exchange membranes to industry have been made. Though the driving force for ions and water to permeate through the membrane at initial stage was primarily electrochemical potential and chemical potential, it is reported in the recent research that hydraulic pressure (ref. 62), temperature difference (ref. 63), difference of proton concentration (ref. 87) and so on are also utilized as the driving force. These recent applications are due to development of the ion exchange membranes of an anisotropic structure or other new types of membranes : charged reverse osmosis membranes, mosaic ion exchange membranes, gas separation membrane having amino groups and so on. Especially tube and hollow fiber type ion exchange membranes are preferable in the case that the driving force is not electrochemical potential. Tokuyama Soda Co. Ltd. has contributed to the research and development of ion exchange membranes and their industrial application. First of all, the applications reported are summarized in Table 1 . As it is impossible to explain all applications in detail, several examples of the applications which Tokuyama Soda Co. Ltd. has developed or participated in the development are given below.

\section{Application of ion exchange membranes to electrodialysis}

The initiative purpose to develop ion exchange membranes for Tokuyama Soda Co. Ltd. was to produce sodium chloride from sea water by electrodialysis. About 360,000 t/year of edible salt is now produced by our technology in Japan. Progress in the technology for

TABLE 1. Application of Ion Exchange Membranes

\begin{tabular}{lll}
\hline Methods & Ion Exchange Membranes used & Purposes \\
\hline
\end{tabular}
Electrodialysis Cation, anion, bipolar
exchange membranes

Electrolysis

Diffusion Dialysis Anion exchange membrane

Donnan Dialysis

Piezodialysis

Reverse Osmosis

Facilitated

Transport

Cell and Battery (mainly)

Cation, anion exchange membranes

Cation exchange membrane (mainly)

Mosaic, amphoteric exchange membranes

Anisotropic cation and anion exchange membranes

Cation, anion exchange membranes

Cation, anion exchange membranes

Cation, anion exchange membranes
Concentration or Desalination of electrolyte solution.

Separation of ionic materials from non-ionic materials.

Production of acid and base by water splitting.

Double decomposition of salt. Sterilization of water etc.

Separator for electrolytes (chloralkali, organic synthesis, water electrolysis etc.).

Recovery of acid from waste acid solution etc.

Recovery of trace amount of ions, ion-exchange etc.

Concentration, desalination and separation of electrolytes.

Desalination, concentration and separation of electrolytes.

Separation between ions with same charge.

Electrolyte of fuel cell, reverse electrodialysis, separator of redox-flow cell and others

Sensor for humidity, proton etc., Pervaporation, Gas separation etc. 
sea water concentration directly reflects the development of our technology. In 1965, the power consumption to make sodium chloride was about $400 \mathrm{kWh} / \mathrm{t}-\mathrm{NaCl}$ and the concentration of sodium chloride in brine attainable was $160 \mathrm{~g} / 1$ then. Figure 9 shows progress of the salt production technology in recent years. Iso-energetic curve, prepared by the Japan Tobacco Corporation Inc., shows that energy cost change due to saving in electric power consumption and brine concentration is expressed by minus. For example, energy costs are equal between the two cases that brine salt concentration is $160 \mathrm{~g} / 1$ and electric power consumption is $270 \mathrm{kWh} / \mathrm{t}-\mathrm{NaCl}$ and that the concentration $170 \mathrm{~g} / \mathrm{l}$ and the power consumption $325 \mathrm{kWh} / \mathrm{t}-\mathrm{NaCl}$. Figure 9 shows that the energy cost saving by our new technology is about 3000 yen/t-NaCl over the conventional technology. Many efforts have been made to reduce energy consumption and to increase concentration of sodium chloride in brine. The new technology shows the energy consumption of $150 \mathrm{kWh} / \mathrm{t}-\mathrm{NaCl}$ when concentration of sodium chloride in brine is $200 \mathrm{~g} / 1$ (ref. 64). This has been achieved due to the decrease in the electric resistance of the membrane, the increase in sodium chloride content in brine and the improvement of the electrodialyzer.

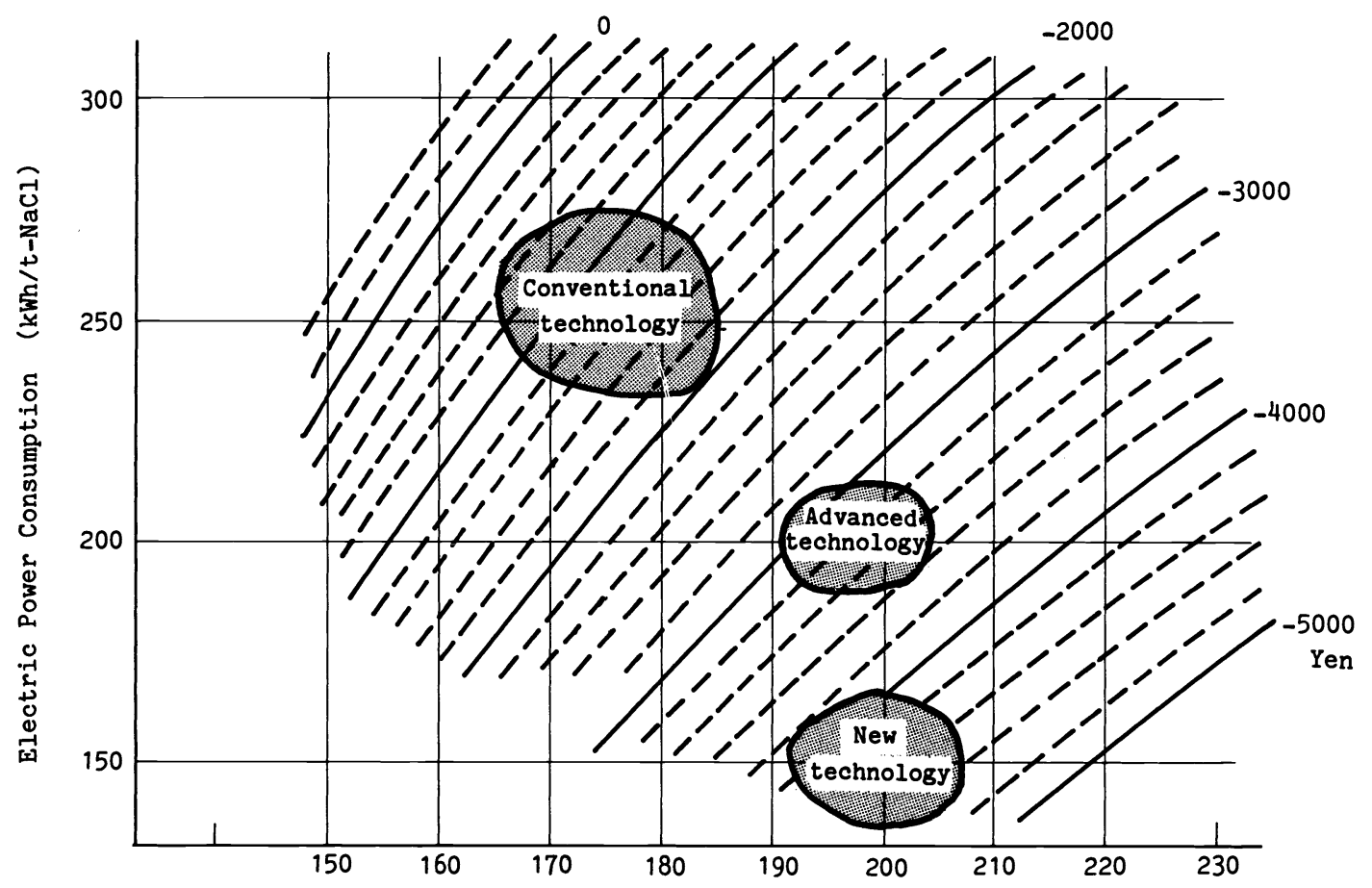

Concentration of concentrated brine $(\mathrm{NaCl} \mathrm{g/l})$

Fig. 9. Energy cost reduction by new technology (iso energetic curve). According to electric power unit price and fuel unit price in November 1985.

It is not difficult to obtain potable water generally in Japan except some special cases. The cases which require the electrodialytic demineralization of water are seen at remote islands, primary pretreatment of water for ion exchange resin demineralization in power generator, potable water making on board small ships and elsewhere. Our company developed a new energy-saving electrodialyzer for demineralization. The energy consumption is about $8-9 \mathrm{kWh} / \mathrm{t}$-water at $25.0^{\circ} \mathrm{C}$ and about $6.0 \mathrm{kWh} / \mathrm{t}$-water at $60.0^{\circ} \mathrm{C}$ in the case of demineralization of sea water (ref. 65). Recent work concerning the electrodialytic demineralization was reported by Ionics Corp. It is reported that electrodialysis reversal (EDR) is effective on protection of membrane from organic fouling and also protection from scaling of low solubility salt such as $\mathrm{CaSO}_{4}$ (ref. 66).

Applications of ion exchange membranes to food industries and medical supplies industries are active. Figure 10 shows examples of applications of membrane technology, not only electrodialysis but also reverse osmosis and ultrafiltration, for dairy industry. Electrodialysis plays an important role in this area (ref. 67). Tokuyama Soda Co. Ltd. has developed the demineralizing technique for dairy industry in collaboration with Snow Brand Milk Production Co. Ltd. (ref. 68) in Japan. The commercial plant for whey demineralization has been operating since 1983 in Hokkaido prefecture of Japan. The electrodialysis plant to demineralize cheese whey was also supplied to the Danish Government Research Institute (DRI) in Denmark. Other applications to food industries are: the demineralization of molasses in order to increase sugar recovery (ref. 69), the acid removal from fruit juice, the separation of amino acid and minerals in amino acid 


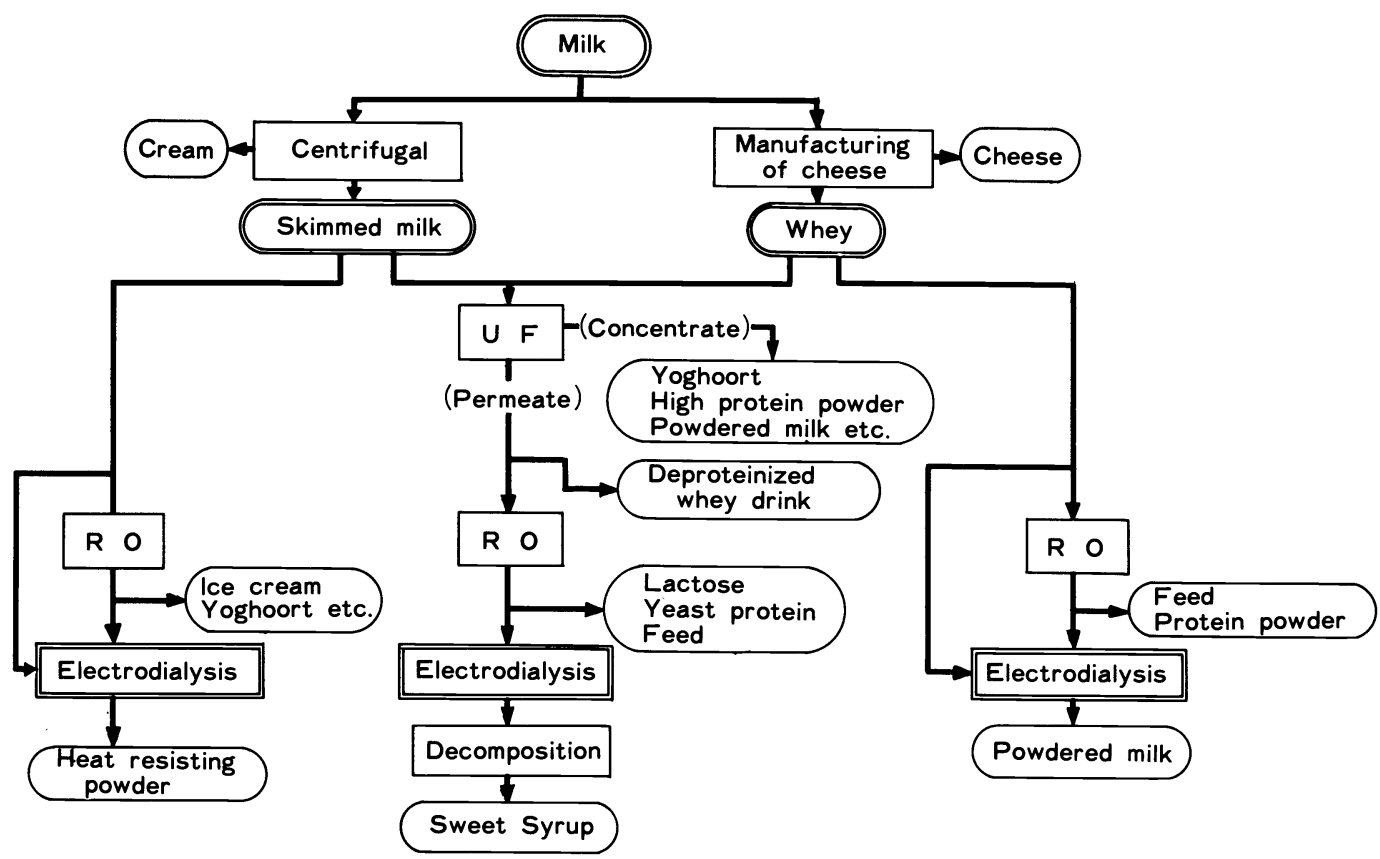

Fig. 10. Application to Dairy Industry.

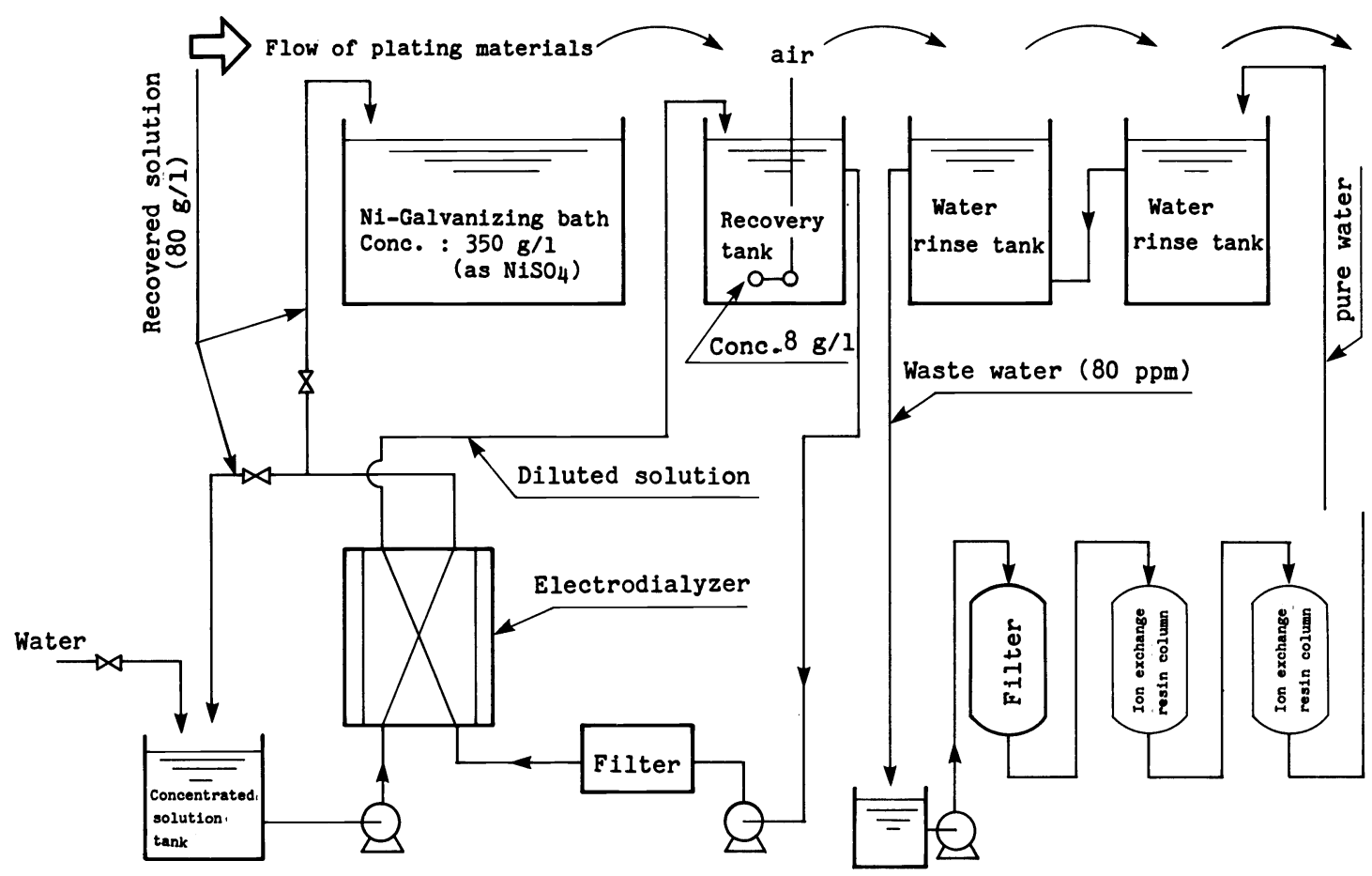

Fig. 11. Flow diagram of treatment of Ni-Galvanization Effluent.

production process (ref. 70,71 ) and so on. It was reported that acid removal by electrodialysis had made grape juice stable against precipitation of potassium tartrate (ref. 72). In these cases, organic fouling of the anion exchange membranes is serious in conventional ion exchange membranes. While there are cases where neutral membranes are used instead of anion exchange membranes, the newly developed anion exchange membranes are 
useful for such purpose from the viewpoint of avoiding the remarkable decrease in the current efficiency.

Treatment of industrial waste water by electrodialysis using NEOSEPTA membranes has contributed to pollution abatement and recovery of valuable materials. For example, the concentrating recovery of nickel galvanization effluent as shown in Fig.11, the treatment of copper, zinc and tin galvanizing liquors and the recovery of noble matels are made efficiently. Similar applications are developer-regeneration by electrodialysis for color paper processing (ref. 73) and electrolytic recovery of silver from photographic fixing solutions and the reuse of the solution by simultaneous treatment of the waste photographic fixing and bleaching solution in a cell (ref. 74).

Other interesting studies of ion exchange membrane applications are bactericidal effect of electrodialysis on $E$. Coli by ion exchange membranes and accelarated fermentation to produce glutamic acid and lactic acid. Bactericidal effect of electrodialysis on E. Coli is observed when the electrodialysis is carried out over the limiting current density and is dependent on cation and anion species contained in the solution. This effect is connected with $\mathrm{pH}$-change of the solution and observed remarkably in the presence of ionic species which permeate easily through the membrane (ref. 75). Accelerated fermentation is made by removing glutamic acid and lactic acid from culture fluid by electrodialysis continuously in order to maintain the concentration of products low (ref. 76). Applications of the electrodialysis to dilute solution are enrichment of trace level ions $\left(10^{-6}-10^{-4} \mathrm{~mol} / 1\right.$; ionic strength is adjusted by $\mathrm{KCl}$ ) (ref. 77) and removal of radioactive ions by multi-step electrodialysis (ref. 78 ).

\section{Application of ion exchange membranes to electrolysis}

Typical example of this case is electrolysis of sodium chloride to produce chlorine, hydrogen and sodium hydroxide (membrane chlor-alkali process). Principle of this process was proposed in 1950 and subsequent development of perfluorocarbon ion exchange membranes led to realize this process. Tokuyama Soda Co. Ltd. has been engaged in research and development of this process. The progress in this technology has been made rapidly. For example, the energy consumption to produce caustic soda in our technology was about 3100 $\mathrm{kWh} / \mathrm{t}-\mathrm{NaOH}$ in 1976, which decreased year by year and attained to the level of $2060 \mathrm{kWh} / \mathrm{t}-$ $\mathrm{NaOH}$ at $30 \mathrm{~A} / \mathrm{dm}^{2}$ in 1982. This approaches to theoretical value estimated as about 1550 $\mathrm{kWh} / \mathrm{t}-\mathrm{NaOH}$. This has been attained by improvement of membrane, electrolyzer and electrolysis methods as well as development of the new cathode of low hydrogen overvoltage. Especially, perfluorocarbon carboxylic acid groups membranes gave high current efficiency in caustic soda production and surface treatment of the membrane served to release bubble from the membrane surface thereby reducing the cell voltage significantly. Tokuyama Soda Co. Ltd. finished the conversion of mercury electrolysis process and diaphragm electrolysis process to membrane process in March of 1985 by own technology. Our technology and electrolyzers were exported to Korea, Taiwan, China and Kuwait. Especially in the Kuwait plant, sodium chloride produced by electrodialysis of sea water is supplied as feedstock to membrane chlor-alkali process. The long cherished dream that reseachers of ion-exchange membrane had aspired for is just about to be realized at this plant.

Ion exchange membrane is used for electrolysis of water to produce hydrogen gas and oxygen gas for utilization of hydrogen energy. In this case, the usage of perfluorocarbon cation exchange membranes and inorganic ion exchange membranes (ref. 20) is reported. Especially, it is reported that Solid Polymer Electrolyte (SPE) method produces hydrogen gas at high efficiency, where perfluorocarbon cation exchange membranes are used with catalyst coated as electrodes (ref. 79). Ion exchange membranes are also used as a separator in organic synthesis by electrolysis. Typical example is hydrodimerization of acrylonitrile to produce adiponitrile (ref. 17). Other various applications to electrolytic organic synthesis have been reported (ref. 80). Tokuyama Soda Co. Ltd. has contributed to this area. Application of SPE electrlysis method to organic synthesis is also reported (ref. 81). There are many other applications of the ion exchange membranes to the electrolysis as separator (ref. 71) : the recovery of precious metal in catholyte by deposition on the cathode, the reduction of uranyl ions to uranous ions by the cathode reaction and so on.

\section{Application of ion exchange membranes to diffusion dialysis}

Acid recovery from waste acid solutions is made by diffusion dialysis using the anion exchange membranes. Table 2 shows the examples of diffusion dialysis applied to acid recovery. Flow rate of the solution in dialyzer is about $1-5 \mathrm{~cm} / \mathrm{min}$. That is minute and is all power consumed for operation. Therefore, this is an energy saving process. The anion exchange membrane for this purpose has been developed by Tokuyama Soda Co. Ltd. i.e., NEOSEPTA AFN (ref. 82). This purpose requires the membrane to be a large permeation of acid, less leakage of metal ions, long service life, high mechanical strength and so on. Especially, industrial recovery of nitric acid and hydrofluoric acid has been retarded because of oxidative deterioration of the anion exchange membrane. Tokuyama Soda Co. Ltd. and Nippon Stainless Steel Co. Ltd. have jointly developed the technology for recovery of these acids by using NEOSEPTA AFN. The first commercial plant for this purpose in Japan 
TABLE 2. Examples of Diffusion Dialysis

\begin{tabular}{ll}
\hline \multicolumn{1}{c}{ Process } & \multicolumn{1}{c}{ Recovered Acids } \\
\hline $\begin{array}{l}\text { Acid recovery from pickling solution } \\
\text { or pickling waste solution of steel }\end{array}$ & $\mathrm{H}_{2} \mathrm{SO}_{4}, \mathrm{HCl}, \mathrm{HNO}_{3}, \mathrm{HF}$ \\
$\begin{array}{l}\text { Purification of battery waste acid } \\
\text { Acid recovery from Alumite process } \\
\text { waste acid solution }\end{array}$ & $\mathrm{H}_{2} \mathrm{SO}_{4}$ \\
$\begin{array}{l}\text { Acid recovery from metal refining process } \\
\text { Treatment of etching waste solution (Al, } \mathrm{Ti})\end{array}$ & $\mathrm{H}_{2} \mathrm{SO}_{4}, \mathrm{HNO}_{3}$ \\
$\begin{array}{l}\text { Acid recovery from surface treatment acid } \\
\text { of electroplating line }\end{array}$ & $\mathrm{H}_{2} \mathrm{SO}_{4}, \mathrm{HCl}, \mathrm{H}_{3} \mathrm{PO}_{4}$ \\
$\begin{array}{l}\text { Purification and acid removal from } \\
\text { organic synthetic process }\end{array}$ & $\mathrm{HCl}, \mathrm{H}_{2} \mathrm{SO}_{4}, \mathrm{HNO}_{3}, \mathrm{HF}$ \\
\end{tabular}

TABLE 3. Operation results of diffusion dialysis plant $\left(\mathrm{HNO}_{3}-\mathrm{HF}\right.$ recovery system)

\begin{tabular}{|c|c|c|c|c|}
\hline & & Items & Results & Targets \\
\hline \multirow{3}{*}{$\begin{array}{l}\text { Acid recovery } \\
\text { rate }\end{array}$} & & $\mathrm{HNO}_{3}$ & Av. 97 & Av. over 87.0 \\
\hline & & $(\%)$ & Av. 50 & Av. over 60.0 \\
\hline & & Fe elimination rate $(\%)$ & Av. 95 & Av. over 90.0 \\
\hline \multirow{9}{*}{$\begin{array}{l}\text { Each } \\
\text { composition }\end{array}$} & \multirow{5}{*}{$\begin{array}{l}\text { Pickl- } \\
\text { ing } \\
\text { waste } \\
\text { acids }\end{array}$} & Flow rate $\left(\mathrm{m}^{3} / \mathrm{H}\right)$ & 0.9 & 0.94 \\
\hline & & $\mathrm{HNO}_{3} \quad(\mathrm{~g} / \mathrm{l})$ & Av. 55 & $40.0-100.0$ \\
\hline & & $(\mathrm{g} / \mathrm{l})$ & Av. 11 & $8.0-25.0$ \\
\hline & & $(\mathrm{g} / \mathrm{l})$ & Av. 21 & $20.8 \sim 40.0$ \\
\hline & & (ppm) & Av. 30 & 200.0 \\
\hline & \multirow{4}{*}{$\begin{array}{l}\text { Recover- } \\
\text { ed acids }\end{array}$} & Flow rate $\left(\mathrm{m}^{3} / \mathrm{H}\right)$ & 0.90 & 0.94 \\
\hline & & $\mathrm{HNO}_{3} \quad(\mathrm{~g} / \mathrm{I})$ & Av. 53 & 34.887 .0 \\
\hline & & $(\mathrm{g} / \mathrm{l})$ & Av. 6 & 4.815 .0 \\
\hline & & $(g / 1)$ & Av. 1.1 & 2.04 .0 \\
\hline
\end{tabular}

began to operate at Kashima factory of Nippon Steinless Steel Co. Ltd. from April, 1984. Table 3 shows the satisfactory operation results of the plant.

Donnan dialysis is also one kind of the diffusion dialysis. Various applications have been proposed : the water-softing by using the cation exchange membranes and sodium chloride solution (ref. 83), the removal of potassium hydroxide from gold plating bath (ref. 84), the removal of hazardous metal ions, pretreatment of ion chromatography in order to concentrate ions (ref. 85) and so on. The ion exchange membranes in the form of tube is effective for this purpose (ref. 86). There is a report on the utilization of $\mathrm{pH}$ difference as the driving force to transport ions through the cation exchange membrane against the concentration gradient (ref. 87). 


\section{Application of ion exchange membranes to cell and battery}

Various applications to cell and battery have been made. The usage of perfluorocarbon sulfonic acid membrane to hydrogen-oxygen fuel cell as the electrolyte is well-known. Other cases are usage of the membrane of the low electric resistance to alkali battery as a separator, where the membrane is made by grafting of acrylic acid to polyethylene, separator for zinc-bromine battery (ref. 88), zinc-chlorine and redox-flow battery (ref. 89). Figure 12 shows principle of redox-flow battery.

Especially, batteries to charge electric energy during off-load time are being developed by a certain institute of Japanese Government (ref. 90). Reverse electrodialysis is also studied (ref. 91). If this process is possible, a large amount of energy will be obtained from membrane potential between river water and sea water. However, it is reported that it is difficult to realize by means of present membrane and technology (ref. 92).
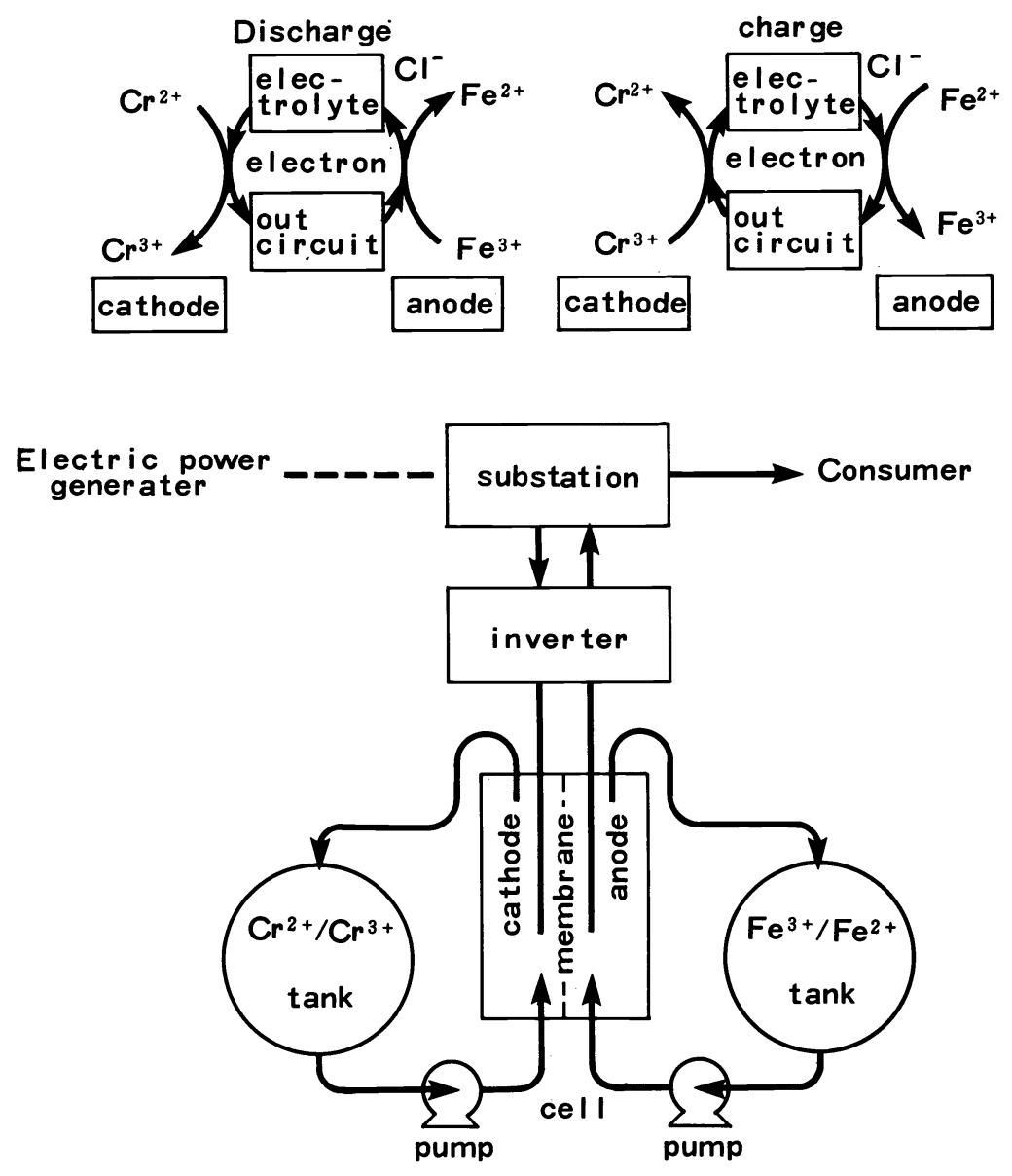

Fig. 12. Principle of redox-flow Battery

\section{Other applications of ion exchange membranes}

Ion exchange membranes are interesting materials because they are polymeric membranes containing ion exchange groups, 1.e., hydrophilic groups. In this respect, applications to pervaporation are now actively pursued : the mixture of water and miscible organic solvent is separated into each component by the method where the mixture is placed on one side of the membrane with the other side kept under vacuum. While ion exchange membrane is not essential in this case, it is effective for this purpose too. Recently, many works are made for application of the ion exchange membranes to the pervaporation (ref. 93). Especially, cation and anion exchange membranes of various ionic forms are examined in the case of separation between ethanol and water. OH-form anion exchange membranes gave the promising results (ref. 94). Various attempts to increase the flux of water or organic solvent and to increase the separation factor have been made (ref. 95). As olefinic compounds react reversibly with silver ions, cation exchange membrane that is ion- 
exchanged with silver ions is expected to separate olefin compounds from alkane compounds. Similarly, carbon dioxide is separable by the cation exchange membrane that is ionexchanged with ethylenediamine (ref. 96). For the purpose of gas separation, the anion exchange membrane derived from poly ( 2.6 -dimethyl - p -phenylene oxide ) shows the oxygen-enriching properties (ref. 97).

Water content of the ion exchange membrane varies with humidity. Therefore the ion exchange membranes are usable as a hygrometer. When water content of the membrane increases with increasing humidity, the increase in the current or ionic conductivity between the electrodes on both sides of the membrane is detectable (ref. 98). Membrane potential is also usable to determine the concentration of ions. There is an example used in high concentration of hydrofluoric acid to determine the concentration (ref. 99). Ion exchange membranes are used as a carrier for photosensitive materials because they have ion exchange groups : photovoltaic behavior of bacteriorhodopsin-loaded cation exchange membranes (ref. 100), photophysical properties of cadmium sulfide loaded on cation exchange membrane (ref. 101) and others (ref. 102).

\section{CONCLUSION}

Separation is one of the most significant processes in chemical industry. Distillation, crystalization and sublimation have been practiced for separation in chemical plants. However technique of membrane separation which does not cause phase conversion calls for increasing attention for energy saving purpose. Ion exchange membranes and their application technology are one of the most advanced method among various membrane technologies.

Significant function of ion exchange membranes is to separate ions efficiently with low energy consumption. There are many requirements for ion exchange membranes : low electric resistance, high permselectivity, low diffusion of salt, low osmotic water, high mechanical strength, high selectivity between ions with same charge, high chemical stability, anti-organic fouling, low cost and so on. It is very difficult to satisfy all of these requirements at the same time. The membrane is therefore designed to be provided with composite requirement-sharing system. For example, reinforced backing fabric, which most commercial membranes have, takes a part of high mechanical strength. Cationic polyelectrolyte layer on the cation exchange membrane takes a part of rejecting multivalent cation on the membrane surface, carboxylic acid groups layer prevents leakage of hydroxide ions and so on. It is considered that this trend will be further intensified to improve the performance of ion exchange membranes.

\section{REFERENCES}

1. R. Fernandez-Prini and P. Schulman, J. Applied Polymer Sci. 29, 341 (1984).

2. K. Kneifel and K. Hattenbach, Desalination, 34, 77 (1980).

3. Y. Mizutani, R. Yamane, H. Ihara and H. Motomura, Bull. Chem. Soc. Japan, 36, 361 (1963); ibid, 38, 689 (1965).

4. J. P. Masson, R. Molina, E. Roth, G. Gaussens and F. Lemaire, Int. J. Hydrogen Energy, 7, 167 (1982); J. M. Widmaier, J. Hubert and G. C. Meyer, J. Polymer Sci. Polymer Letter. 19, 457 (1981).

5. L. Levy, M. Muzzi and H. D. Hurwitz, J. Chem. Soc. Faraday Trans 1, 78, 1001 (1982); R. E. Uschold, J. Applied Polymer Sci. 29, 1335 (1984).

6. E. A. Hegazy, A. M. Dessouki, A. M. Rabie and I. Ishigaki J. Polymer Sci. Polymer Chem. 22, 3673 (1984).

7. H. Omichi and J. Okamoto, J. Applied Polymer Sci. 30, 1277 (1985) ; B. Chakravorty, R. N. Mukherjee and S. Basu, Desalination, 46, $353(1983)$.

8. R. Y. M. Huang and J. J. Kim, J. Applied Polymer Sci. 29 4017, 4029 (1984).

9. A. Bottino, G. Capannelli and S. Munari, J. Applied Polymer Sci. 30, 3009 (1985).

10. N. Sivashinsky and G. B. Tanny, J. Applied Polymer Sci. 28, 3235 (1983); P. Zschocke and D. Quellmalz, J. Membrane Sci. 22, 325 (1985) ; W. H. Daly, J. Macromol. Sci. Chem. A22, 713 (1985).

11. T. Sugano, M. Kamemura and N. Yamamoto, Japan Kokai Tokkyo Koho (unexamined application) JP 59-202227, 60-32832.

12. W. Rozek-Galina and W. Trochimczuk, J. Membrane Sci. 22, 47 (1985) ; A. D. Dimov and I. Alexcandrova, Desalination, 46, 361 (1983).

13. T. Uragami, H. Fujimoto and M. Sugihara, Desalination, 34, 311 (1980); K. Koyama, E. Kimura, I. Hashida and M. Nishimura, J. Applied Polymer Sci., 29, 2929 (1984).

14. T. Sata, Y. Kagiyama, F. Hamada and K. Takata, Japan Kokai Tokkyo Koho (unexamined application) JP 58-76144; V. Kudela, J. Vacik and J. Kopecek, J. Membrane Sci. $123(1980)$.

15. "Perfluorinated Ionomer Membranes", ACS Symposium Series 180, P 365, 411, 427 (1982) edited by A. Eisenberg and H. L. Yeager ; J. H. Austin, "Nafion Perfluorinated Membranes, Operation in Chlor-Alkli Plants", Presented at Society for the Chemical Industry, Third London International Chlorine Symposium, June $5-7$ (1985).

16. T. Sata, K. Motani and Y. Ohashi, "Ion Exchange Membranes", P 137 (1983) Ellis 
Horwood Ltd.

17. M. Seko, S. Ogawa, M. Yoshida and H. Shiroki, Dechema-Monographien Band 97, p 27 (1984).

18. K. Matsui, H. Kikuchi, A. Akimoto et al, Japan Kokai Tokkyo Koho (unexamined application) JP 59-122520.

19. G. Alberti, M. Casciola and U. Costantino, J. Membrane Sci. 16, 137 (1983).

20. H. Vandenbarre, R. Leysen and H. Nackaerts, Int. J. Hydrogen Energy 8,81 (1983).

21. T. Sata, R. Izuo and F. Kurokawa, Japan Tokky Koho (examined application) JP 54-17713 ; T. Takata, Japan Kokai Tokkyo Koho (unexamined application) JP 55-86821 ; L. T. C. Lee and K. J. Liu, USP 4355116 (Allied Corp.).

22. J. Kassotis, H. P. Gregor and F. P. Chlanda, J. Electrochem. Soc. 131, 2810 (1984).

23. T. Kiyota, A. Akimoto, K. Matsui et al, Japan Kokai Tokkyo Koho (unexamined application) JP 60-1234.

24. C\&E News, December 23, 1985.

25. I. C. Bassignana and H. Reiss, J. Membrane Sci. 15, 27 (1983).

26. R. Yamane, R. Izuo and Y. Mizutani, Denki Kagaku 33 , 589 (1965).

27. O. Yano and Y. Nada, J. Applied Polymer Sci. 25,1723 (1980) etc.

28. R. Jerome and V. Desreux, J. Applied Polymer Sci. 15, 199 (1971) etc.

29. T. Eguchi and S. Mori, Japan Tokkyo Koho (examined application) JP 60-8012.

30. Y. Miyamoto and T. Fujimoto, Maku (Membrane) 8,212 (1983) ; K. Ishizu, K. Inagaki and T. Fukutomi, J. Polymer Sci., Polymer Chem, 23, 1099 (1985) ; S. Takahashi, K. Matsumura, M. Toda, T. Fujimoto, H. Hasegawa and Y. Miyaki, Polymer J. 18, 41 (1986).

31. K. Ishizu and T. Fukutomi, J. Polymer Sci. Polymer Letter $2 \overline{3,219(1985)}$.

32. T. Fujimoto, Y. Isono and Y. Miyaki, Fr. Demande, FR 2505326.

33. J. A. Cox, R. Gajek, Analytica Chimica Acta, 144, 239 (1982).

34. G. Btazejewska-Wiśniewska and T. Winnicki, Desalination, 38, 461 (1981).

35. T. Sata, J. Colloid Interface Sci. 44, $393(1973)$; T. Sata, R. Yamane and Y. Mizutani, J. Polymer Sci. Polymer Chem. 17, 2071 (1979).

36. T. Gunjima and Y. Sugano, Japan Tokkyo Koho (examined application) JP 48-34999, 531071 .

37. T. Shimidzu, M. Yoshikawa, M. Hasegawa and K. Kawakatsu, Macromolecules, 14,170 (1981).

38. Y. Imashiro, H. Yokoi, M. Yoshikawa, K. Sanui and N. Ogata, Nippon Kagaku Kaishi, 875 (1983).

39. C. Fabiani, L. Bimbi, M. De Francesco and B. Scuppa, J. Electrochem. Soc. 132,872 (1985).

40. J. Rubinstein, A. Warahawsky, L. Schechtman and 0. Kedem, Desalination, $\underline{51,55}$ (1984).

41. T. Sata, Colloid \& Polymer Sci. 256, 62 (1978).

42. T. Sata and Y. Mizutani, J. Polymer Sci. Polymer Chem. 17, 1199 (1979).

43. T. Sata, Y. Kagiyama, F. Kurokawa and K. Takata, Japan Kokai Tokkyo Koho (unexamined application) JP 55-78021 ; K. Urano, T. Ase and Y. Naito, Desalination 51, 213 (1984).

44. Y. Mizutani and M. Nishimura, J. Applied Polymer Sci. 14, 1847 (1970) ; Y. Kagiyama, K. Shikata and Y. Mizutani, J. Applied Polymer Sci. 23, 1309 (1979).

45. D. G. Peiffer, B. L. Hager, R. A. Weiss, D. K. Agarwal and R. Lundberg, J. Polymer Sci. Polymer Physics, 23, 1869 (1985).

46. R. Vasquez, J. Avalos, F. Volino, M. Pineri and D. Galland, J. Applied Polymer Sci. 28, 1093 (1983).

47. N. G. Boyle, V. J. McBrierty and D. C. Douglas, Macromolecules, 16, 75 (1983).

48. N. G. Boyle, V. J. McBrierty and A. Eisenberg, Macromolecules, $1 \overline{6}, 80$ (1983).

49. W. Y. Hsu, Macromolecules, 16, 745 (1983).

50. K. A. Mauritz and C. L. Gray, Macromolecules, 16, 1279 (1983).

51. N. G. Boyle, J. M. D. Coey, A. Meagher, V. J. McBrierty, Y. Nakano and W. J. MacKnight, Macromolecules, 17, 1331 (1984).

52. G. Zundel, J. Membrane Sci. 11, 249 (1982).

53. T. D. Gierke and W. Y. Hsu, "Perfluorinated Ionomer Membranes", ACS Symposium Series 180, P 283. (1982).

54. R. W6dzki, A. Narebska and W. K. Nioch, J. Applied Polymer Sci., 30, 769 (1985) ; V. K. Datye and P. L. Taylor, Macromolecules, 17, 1704 (1984) ; ibid. 18, 1479 (1985);

M. N. Szentirmay, N. E. Prieto and C. R. Martin, J. Phys. chem., $89, \overline{30} 17$ (1985).

55. R. Al-Jishi, V. K. Datye and P. L. Taylor, Macromolecules, 18, 297 (1985).

56. W. Y. Hsu and T. Berzins, J. Polymer Sci. Polymer Physics, 23,933 (1985).

57. R. S. Yeo, J. Electrochem. Soc., 130, 533 (1983).

58. R. Hidalgo-Alvarez, F. J. de las Nieves and G. Pardo, J. Colioid Interface Sci., 107, 284 (1985) ; V. K. Indusekhar and N. Krishnaswamy, Desalination, 52, 309 (1985).

59. C. Fabiani, G. Scibona and B. Scuppa, J. Membrane Sci., 16, 51 (1983).

60. T. Kyu and A. Eisenberg, J. Polymer sci. Polymer Letter., 21, 589 (1983).

61. H. K. Pan, D. J. Yarusso, G. S. Knapps and S. L. Cooper, Proc-Electrochem soc. 83-3 (1983).

62. J. Ceynowa, Angew. Makromol. Chem., 127, 187 (1984).

63. M. Tasaka, K. Kishi and M. Okita, J. Membrane Sci., 17, 149 (1984).

64. K. Doi, E. Asada, H. Mishima and M. Yamamoto, Presented at 34 th annual meeting of The 
Society of Sea Water Sci. (June, 15-16, 1983).

65. M. Urabe and Y. Tani, Zōsui Gijitsu (Water Production Technology), 6, 67 (1980).

66. S. D. Strauss, Power 129,72 (1985).

67. S. Okonogi, Nippon Shokuhin Kogyo Gakkaishi, 32, 144 (1985).

68. Y. Kobuchi and H. Motomura, "Demineralization of whey by multistage continuous electrodialysis system", Presented at The International Membrane Technology Conference, Nov., 8-10 (1983), Sydney, Australia.

69. T. Yamauchi et al. Int. Sugar J., 87, 3 (1985); U. S. P. 4,492,601 (Daiichi Seito et al) etc.

70. H. Odagiri, Shokuhin Kogyo, 1983, 20 (1983).

71. T. Sata, Nenryo oyobi Nensho (Fuel and Combustion), 51, 166 (1984).

72. G. Niketic-Aleksic and M. M Jaksic, Desalination, $3 \overline{5}, 317$ (1980).

73. M. Yamada, S. Matsushita, H. Hirai, I. Tsuyuki and Y. Ogawa, J. Applied Photographic Eng., 7, 53 (1981).

74. A. Tasaka, T. Yasuzawa, Y. Nagafuji, A. Yamano, H. Miyazaki, H. O-oka and H. Sugimoto, Denki Kagaku, 53, 466 (1985) ; ibid. 53, 400 (1985); ibid. 53 , 404 (1985).

75. T. Sato, T. Tanaka and T. Suzuki, Denki Kagaku, $\frac{53}{53}, 706$ (1985).

76. M. Iwahara, H. Takamoto, Y. Nomura and M. Motoe, Presented at Meeting of Nishinihon Shibu of Agricutural Society of Japan (Oct. 3. 1981 at Shimane Univ.) etc.

77. J. A. Cox and R. Carlson, Analytica Chimica Acta, 130, 313 (1981).

78. S. Sugimoto and H. Aikawa, Nihon Genshiryoku Gakkai Shi, 22, 813 (1980).

79. E. Torikai and K. Takenaka, Soda to Enso, 33, 51 (1982) ; Denki Kagaku, 51,633 (1983).

80. Electro Organic Synthesis Technology, M. Kranpelt, AICHE, Symposium Series 185,25 (1979).

81. Z. Ogumi, S. Ohhashi and Z. Takehara, Electrochim. Acta, 30, 121 (1985) ; Z. Ogumi, Kagaku Kogyo, 40, 740 (1985).

82. Y. Kobuchi, H. Motomura, Y. Noma and F. Hanada, J. Membrane Sci, in press ; J. Sato, M. Onuma, H. Motomura and Y. Noma, Metal Finishing Society of Japan, 32, 220 (1985).

83. B. S. Joshi and K. P. Govindan, Desalination, 38, 509 (1981).

84. H. H. Law, Plat Surf. Finish, 70,72 (1983).

85. J. E. DiNunzio and M. Jubara, Anal. Chem., 55, 1013 (1983).

86. J. A. Cox and G. R. Litwinski, Anal. Chem., 55,1640 (1983).

87. H. Oaki, M. Ishida and T. Shirai, J. Chem. Engineering Japan, 13, 251 (1980).

88. H. S. Lim, A. M. Lackner and R. C. Knechtli, J. Electrochem. Soc., 124, 1154 (1977); F. G. Will, J. Electrochem. Soc., 126, 36 (1979) ; V. S. Donepudi and B. E. Conway, J. Electrochem. Soc. $84,1477(1984)$.

89. H. Ohya, K. Emori, T. Onto, Y. Eegishi and K. Matsumoto, Denki Kagaku, 53, 462 (1985) ; H. Ohya, K. Emori, T. Ohto and Y. Negishi, Denki Kagaku, 52, 341 (1984) ; D. Oei, J. Applied Electrochemistry, 15, 231 (1985) ; P. S. Fedkiw and R. W. Watts, J. Electrochem. Soc., 131, 701 (1984).

90. T. Ozawa, Kagaku to Kogyo, 37, 679 (1984).

91. R. Audinos, J. Power Sources, 10,203 (1983).

92. G. D. Mehten, J. Membrane Sci., 11, 107 (1982).

93. G. Tealdo, G. Castello, G. D'Amato and S. Munari, J. Membrane Sci., 11, 3, (1982); M. Hirata, T. Ishikawa, M. Hirao, S. Kobayashi and T. Yoshida, Japan Kokai Tokkyo Koho (unexamined application) JP 54-33278, 33279.

94. A. Wenzlaff, K. W. Boddeker and K. Hattenbach J. Membrane Sci., 22, 333 (1985).

95. H. Ukihashi, T. Asawa, M. Yamabe and H. Miyake, Japan Kokai Tokkyo Koho (unexamined application) JP 58-92405, 58-92407, 58-92408, 58-92413 etc.

96. O. H. Le Blanc. Jr., W. J. Ward, S. L. Matson and S. G. Kimura, J. Membrane Sci., 6 , 339 (1980).

97. T. Yamada, K. Sugie and T. Yamaji, Japan Tokkyo Kokai Koho (unexamined application) JP 57-117321.

98. D. D. Lawson, U. S. P. 4083765 ; N. Kinjo, S. Ohara, T. Sugawara and S. Tsuchitani, Polymer J., 15, 621 (1983).

99. T. Eriksson and G. Johansson, Analytica Chimica Acta, 63, 445 (1973).

100. S. R. Caplan and G. Fischer, J. Membrane Sci. 16, 391 (1983).

101. J. P. Kuczynski, B. H. Milosavljevic and J. K. Thomas, J. Phys. Chem. 88, 980 (1984).

102. P. C. Lee and D. Meisel, J. Am. Chem. Soc. 102, $5477(1980) ;$ P. C. Lee and M. A. J. Rodgers, J. Phys. Chem. 88, 4385 (1984). 